\title{
Fear of falling in obese women under 50 years of age: a cross-sectional study with exploration of the relationship with physical activity
}

\author{
Gilly Rosic ${ }^{1}$, Anne M. Milston ${ }^{2}$, Jim Richards ${ }^{3}$ and Paola Dey ${ }^{4^{*}}$ (1)
}

\begin{abstract}
Background: An understanding of capacity for physical activity in obese populations should help guide interventions to promote physical activity. Fear of falling is a phenomenon reported in the elderly, which is associated with reduced mobility and lower physical activity levels. However, although falls are reportedly common in obese adults, fear of falling and its relationship with activity has not been investigated in younger obese populations.

Methods: In a cross-sectional study, fear of falling was measured in 63 women aged 18 to 49 years, with mean BMI $42.1 \mathrm{~kg} / \mathrm{m}^{2}$ (SD 10.3) using the Modified Falls Efficacy (MFES), the Consequences of Falling (COF) and the Modified Survey of Activities and Fear of Falling in the Elderly (MSAFFE) scales. The choice of scales was informed by prior qualitative interviews with obese younger women. Physical activity levels were measured the same time using the International Physical Activity Questionnaire. The mean score for fear of falling scales, with $95 \%$ confidence intervals, were estimated. Chi-square tests and t-tests were used to explore differences in age, body mass index and fear of falling scores between fallers and non-fallers. For each fear of falling scale, binomial logistic regression was used to explore its relationship with physical activity.

Results: Mean scores suggested high levels of fear of falling: MFES [mean 7.7 (SD 2.7); median 8.5]; COF [mean 31.3 (SD 9.4)]; MSAFFE [mean 25.9 (SD 8.7); median 23]. Scores were significantly worse in fallers $(n=42)$ compared to non-fallers $(n=21)$. MFES and MSAFFE were independently associated with lower levels of physical activity [odds ratio $=0.65,95 \% \mathrm{Cl} 0.44$ to 0.96 and odds ratio $=1.14,95 \% \mathrm{Cl} 1.01$ to 1.28 respectively], when adjusted for age, $\mathrm{BMI}$ and depression.

Conclusions: This study confirms that fear of falling is present in obese women under 50 years of age. It suggests that it is associated with low levels of physical activity. These novel findings warrant further research to understand capacity for physical and incidental activity in obese adults in both genders and suggest innovative interventions to promote lifestyle changes and/or consideration of falls prevention in this population.
\end{abstract}

Keywords: Obesity, Fear of falling, Physical activity, Postural balance, Self-efficacy

\footnotetext{
* Correspondence: Paola.Dey@edgehill.ac.uk

${ }^{4}$ Faculty of Health and Social Care, Edge Hill University, Road, Ormskirk, St

Helens, Lancashire L39 4QP, UK

Full list of author information is available at the end of the article
}

(c) The Author(s). 2019 Open Access This article is distributed under the terms of the Creative Commons Attribution 4.0 International License (http://creativecommons.org/licenses/by/4.0/), which permits unrestricted use, distribution, and reproduction in any medium, provided you give appropriate credit to the original author(s) and the source, provide a link to the Creative Commons license, and indicate if changes were made. The Creative Commons Public Domain Dedication waiver (http://creativecommons.org/publicdomain/zero/1.0/) applies to the data made available in this article, unless otherwise stated. 


\section{Background}

Increasing physical activity in obese adults is a key component of weight management for adults who are obese [1]. However, compliance with physical activity interventions is low. Lack of motivation is not the only barrier to physical activity in obese adults, who also report other concerns such as musculoskeletal pain, fear of movement and low mood [2, 3]. In addition, obese adults are more likely to report falls and balance problems [4-6]. These concerns are also seen in the elderly with 'fear of falling', a phenomenon that has been inconsistently defined but encompasses a number of related concepts, such as, lack of confidence in undertaking activities because of concerns about falling, activity avoidance because of concerns about falling and concerns about the consequences of falling [7]. In the elderly, 'fear of falling' has been shown to lead to mobility restrictions and reduced physical activity, both among those who have fallen and among those who have not, particularly in those with a body mass index over 40 [8-10]. There is an increasing body of literature showing increased levels of 'fear of falling' in other conditions that can affect balance, such as, stroke, or are associated with chronic musculoskeletal pain, such as, fibromyalgia [11, 12]. The primary objective of this study was to measure fear of falling levels, using validated tools, in younger obese adults (under the age of 50 years). We expected that younger obese adults would have elevated fear of falling as measured by the validated tools. We also explored whether greater fear of falling was associated with lower levels of physical activity in this population.

\section{Methods}

This was a cross-sectional study. We recruited from weight management services in North West England. We included women aged 18 to 49 years of age with a body mass index over $30 \mathrm{~kg} / \mathrm{m}^{2}$. We excluded women with known conditions that could affect their balance from the study. Weight management staff approached women to take part and, if they agreed, the participant self-completed an anonymised questionnaire, returned by post. Weight management staff recorded women's most recent body mass index, using weight and height as measured in the clinic, on this questionnaire. The questionnaire included questions on the frequency of falls in the last 12 months; activity levels measured using the short form International Physical Activity Questionnaire (SF-IPAQ) [13]; mood measured using the subscales of the Hospital Anxiety and Depression Scale (HADS) [14], and three questionnaires covering different aspects of fear of falling. The SF-IPAQ is well validated and has been used to measure activity levels in populations who are obese $[15,16]$; established thresholds were used to categorise participants into one of three activity level groups using well-established cut-offs: low, moderate or high [13]. Verbal consent was obtained from the participant as they self-completed the questionnaire and return of the anonymised questionnaire was evidence of implied consent; this was approved by the ethics committee. Ethics committee approval stipulated collection of age group, rather than age year, to facilitate anonymity. We had no permission to identify potentially eligible participants.

Choice of fear of falling scales: There are no fear of falling scales developed for adults who are obese. Therefore, the choice of fear of falling scales was guided by interviews undertaken previously by the lead author with 12 women under 50 years of age with BMI above $30 \mathrm{~kg} / \mathrm{m}^{2}$ from the same weight management services [17], and by a systematic review of fear of falling scales developed for elderly populations [18]. No single scale covered all the concerns raised by the interviewees, so three questionnaires were chosen to cover different aspects.

Modified Falls Efficacy Scale: In the interviews, women frequently mentioned that they had concerns about falling when getting in and out of bed, using public transport, and using steps outside the house. These activities are in the Modified Falls Efficacy Scale (MFES) [19]. There are 14 questions on different activities in the MFES. Each item is answered on a scale of one to 10, in which one is not confident at all and 10 is completely confident. An overall score is estimated by adding the scores for each item and dividing by the number of items; a lower mean score suggests more fear of falling; a threshold of less than 8 has been used to denote presence of fear of falling [19].

Consequence of Falling Scale: Women in the interviews raised concerns about the consequences of falling; these included concerns about injury and pain but also about feeling foolish or embarrassed. Therefore, the questionnaire included the Consequence of Falling Scale (COF) [20]. This scale measures how worried people are about 12 different consequences if they fall over, and includes questions on worries about pain, severe injury, feeling foolish and being embarrassed. Each question is answered on a Likert-type scale (strongly disagree /disagree /agree /strongly agree), and scored one to 4 with the higher score denoting more problem. The scores are added up across the scale to give a total score and a score for each of two subscales (6 questions each): Loss of Functional Independence and Damage to Identity.

Modified Survey of Activities and Fear of Falling in the Elderly Scale: Some interview participants reported on how their concerns about falling, or its consequences, had led to a reduction in undertaking activity or avoidance of exercise or leisure-time activities. Therefore, the Modified Survey of Activities and Fear of Falling in the Elderly Scale (MSAFFE) was included as this covers 
whether people would never, sometimes or always avoid 17 different activities [20, 21]. The item scores $(1=$ 'never avoid', 2 = 'sometimes avoid', 3 = 'always avoid') are added to produce a total score.

For both the latter scales, a higher score denotes more fear of falling but there are no reported thresholds. All the chosen scales have high internal consistency, but only the MFES has excellent test-retest reliability [18].

Sample size: there was limited information to inform sample sizes for this study. There were two studies reporting the mean MFES in elderly fallers [19, 22]. The standard deviations (SD) of the mean MFES in these studies were 1.68 and 2.21. To achieve a precision of $+/-0.5$ around the mean with $95 \%$ confidence, a sample size of either 75 or 43 respectively was needed. The study aimed to achieve at least the lower estimate and no more than the higher estimate. Participant recruitment commenced in 2014 for six months.

Analysis: in the event of one or two missing values on the HADS or a fear of falling scale, the total score was imputed based on the other values. The mean (SD) of fear of falling scales, and subscales, with 95\% confidence intervals (CI) were estimated. Chi-square tests and $\mathrm{t}$-tests were used to explore differences in age, body mass index and fear of falling scores between fallers and non-fallers. For each fear of falling scale, binomial logistic regression was used to explore its relationship with physical activity. Analysis was limited to women with a full dataset for the variables of interest. Separate analyses were undertaken for each scale because the approach was exploratory and there is potentially overlap between the different scales. This was supported by high correlations between the scales $(r=-0.56$ for MFES and COF, $r=-0.76$ for MSAFFE and MFES and $r=0.81$ for COF and MSAFFE). Age and body mass index were included in the analyses, as these variables are associated with lower levels of physical activity [23]. Physical activity was collapsed into two subgroups (low activity and moderate/high activity) as the concern in this population is about low levels of activity. Age groups were collapsed into three groups (18 to 34 years, 35 to 44 years and 45 years and over) as this these groupings have some context in terms of life course and functional decline, e.g., early adulthood (18 to 34 years) and peri menopause/ menopause ( 45 years and over) [24]. This strategy also ensured sufficient numbers in each category for analytical purposes. Body mass index was included as a continuous variable. Anxiety and depression subscales of the HADS were highly correlated $(\mathrm{r}=0.77, P<0.001)$ and anxiety is considered a key component of fear of falling [25]. Therefore, only the depression subscale scores, as a continuous variable, were included in the regression analyses. The mediating impact of a previous history of self-reported falls was also explored.

\section{Results}

In total, 63 women agreed to participate in the study. Their characteristics are shown in Table 1 . Twenty-six (41\%) women were under 40 years of age and body mass ranged from 30.0 to $76.6 \mathrm{~kg} / \mathrm{m}^{2}$ (mean $42.1 \mathrm{~kg} / \mathrm{m}^{2}$ (SD10.3) (Table 1). Anxiety levels were high (mean 10.1 (SD 4.8)). In total, two-thirds $(n=42,67 \%, 95 \%$ CI $56 \%$ to $79 \%$ ) reported that they had fallen in the previous 12 months, of whom 28 (67\%) had fallen more than once. Of the 63 participants, 58 (92\%) completed the SF-IPAQ

Table 1 Characteristics of 63 women participating in the study

\begin{tabular}{|c|c|}
\hline Characteristic & \\
\hline \multicolumn{2}{|l|}{ Age in years $\mathrm{n}(\%)$} \\
\hline 18 to 24 & $3(4.8 \%)$ \\
\hline 25 to 29 & $6(9.5 \%)$ \\
\hline 30 to 34 & $9(14.3 \%)$ \\
\hline 35 to 39 & $8(12.7 \%)$ \\
\hline 40 to 44 & $13(20.6 \%)$ \\
\hline 45 to 49 & $24(38.1 \%)$ \\
\hline \multicolumn{2}{|l|}{ Body mass index $\mathrm{kg} / \mathrm{m}^{2} \mathrm{n}(\%)$} \\
\hline $30-34.9$ & $16(24.4 \%)$ \\
\hline $35-39.9$ & $17(27.0 \%)$ \\
\hline $40-44.9$ & $17(27.0 \%)$ \\
\hline$>45$ & $13(20.6 \%)$ \\
\hline Mean (SD) & $42.1(10.3)$ \\
\hline Range & 30 to 76.6 \\
\hline \multicolumn{2}{|c|}{ Mean (SD) Hospital and Depression Scale scores } \\
\hline Anxiety subscale & $10.1(4.9)$ \\
\hline Depression subscale & $7.5(4.8)$ \\
\hline \multicolumn{2}{|l|}{ Self-reported falls in previous year $n(\%)$} \\
\hline Fallen once & $14(22.2 \%)$ \\
\hline Fallen more than once & $28(44.4 \%)$ \\
\hline \multicolumn{2}{|l|}{ Physical activity level n (\%) 5 missing } \\
\hline Low & $26(44.8 \%)$ \\
\hline Medium & $21(36.2 \%)$ \\
\hline High & $11(19.0 \%)$ \\
\hline \multicolumn{2}{|l|}{ Fear of Falling scale scores } \\
\hline \multicolumn{2}{|l|}{ Modified Falls Efficacy Scale } \\
\hline Mean (SD) & $7.7(2.7)$ \\
\hline Median (IQR) & 8.5 (5.7 to 8.5$)$ \\
\hline Mean (SD) Consequences of Falling Scale & $31.3(9.4)$ \\
\hline Damage to Identity & $17.8(4.5)$ \\
\hline Loss of Functional Independence & $13.6(5.5)$ \\
\hline \multicolumn{2}{|c|}{ Modified Survey of Activities and Fear of Falling in the Elderly Scale } \\
\hline Mean (SD) & $25.9(8.7)$ \\
\hline Median (IQR) & 23 (18 to 34$)$ \\
\hline
\end{tabular}


adequately to assign activity level, of whom 26 (45\%) had low activity levels. The mean scores on the three fear of falling scales are also in Table 1.

Fear of falling scores: The mean score for the MFES [7.7 (SD 2.7); 95\% CI 7.0 to 8.3] was lower than the threshold denoting 'fear of falling'. For the MFES, a lower score denotes more fear of falling. In total, 30 (48\%) of participants had a score lower than eight. Eleven of the 14 items had a mean score less than 8, of which the lowest was for confidence when using public transport. The mean COF score was 31.3 (SD 9.4; $95 \%$ CI 29.1 to 33.6), with the mean score for the Damage to Identity subscale being statistically significantly higher than the mean score for the Loss of Functional Independence subscale (17.8 (SD 4.41) vs 13.6 (SD 5.52); paired t-test 9.31, df62, $p<0.001)$. The highest individual item mean scores in the COF were for 'I will be embarrassed' (mean 3.4), 'I will feel foolish' (mean 3.2) and 'I will be in pain' (mean 3.1) in the Damage to Identity subscale. The mean score for the MSAFFE was 25.9 (SD 8.7; $95 \%$ CI 23.9 to 28.1 ) and the item with the highest mean score was avoid going 'out when it is slippery' (mean 2.2).

Comparison of fear of falling between fallers and non-fallers: Participants who reported a previous fall $(n=42)$ had significantly worse mean scores, suggesting greater fear of falling, on all three scales than those who had not previously fallen $(n=21)$ (Table 2$)$. Both subscales of the COF showed worse scores in those who had fallen (Table 2) but the absolute and relative difference was greater for the Loss to Functional Independence subscale (15.2 vs 10.4; relative difference $50 \%$ ) than for the Damage to Identify subscale (19.0 vs 15.3 ; relative difference 24\%). Indeed, the biggest difference in the item scores was for the item 'continue be active', which is part of the Loss to Functional Independence subscale, but there was no significant difference between groups in the worst scoring items: 'I will be embarrassed' and 'I will feel foolish, which are part of the Damage to Identity subscale. A previous fall was not associated with age or body mass index in this sample (Table 2).

Relationship between fear of falling and physical activity (Table 3): The relationship between fear of falling and physical activity was explored in the 58 women with activity data. MFES score was an independent predictor of low physical activity. There was a $35 \%$ increase in low activity with each unit decrease in MFES score after adjusting for age, BMI and depression (odds ratio $=0.65,95 \%$ confidence interval 0.44 to $0.96, p=0.03-$ Table 3 ); none of the other factors were independent risk factors. After adjusting for the other factors, MSAFFE score was an independent predictor of low physical activity, with a $14 \%$ increase in low activity with each unit increase in MSAFFE score (odds ratio $=1.14,95 \%$ confidence interval 1.01 to $1.28, p=0.04$ ). In addition, older age was also found to be an independent predictor, with a 5 times increase in odds for those aged 45 years or over compared to those aged less than 35 years (odds ratio $=5.1,95 \% \mathrm{CI} 1.04$ to $24.55, \mathrm{p}=0.04$ ) (Table 3). The overall COF score was not found to be an independent predictor of low physical activity (odds ratio $=1.08$, $95 \%$ CI 0.99 to $1.18, p=0.07$ ). The MFES and MSAFFE remained independent predictors of low physical activity even when further adjusted for self-reported falls, the presumptive mediator of fear of falling [OR 0.57 (95\% CI 0.36 to 0.91 ), OR 1.17 (95\% CI 1.04 to 1.34 )] (Table 3). Of the two subscales of the COF, a higher Loss to Functional Independence COF subscale score was significantly associated with low activity (odds ratio $=1.17,95 \% \mathrm{CI} 1.01$ to $1.35, p=0.033)$, when adjusted for all other factors.

Table 2 Comparisons in demographic factors and fear of falling scores between self-reported fallers and non-fallers

\begin{tabular}{|c|c|c|c|}
\hline Characteristic & $\begin{array}{l}\text { Fallers } \\
n=42 \\
\text { Mean (SD) }\end{array}$ & $\begin{array}{l}\text { Non-fallers } \\
n=21 \\
\text { Mean (SD) }\end{array}$ & $\begin{array}{l}\text { Test of difference, } \\
p \text { value } \\
95 \% \mathrm{Cl} \text { for difference }\end{array}$ \\
\hline Mean (SD) BMl in kg/m² & $43.8(10.9)$ & $39.8(8.2)$ & $\mathrm{t}=0.86, \mathrm{df} 61, p=0.70$ \\
\hline \multicolumn{4}{|l|}{ Age group in years } \\
\hline 18 to 35 & $13(31 \%)$ & $5(24 \%)$ & Chi-square $1.29, \mathrm{df} 2$, \\
\hline 35 to 44.9 & $12(29 \%)$ & $9(43 \%)$ & $p=0.52$ \\
\hline$>=45$ & $17(40 \%)$ & $7(33 \%)$ & \\
\hline Mean (SD) Modified Falls Efficacy Scale & $7.0(2.6)$ & $9.0(2.4)$ & $\begin{array}{l}\mathrm{t}=3.12, \mathrm{df} 61, p=0.003 \\
95 \% \mathrm{Cl}-3.4 \text { to }-0.7\end{array}$ \\
\hline Mean (SD) Consequences of Falling Scale & $34.1(8.6)$ & $25.7(8.6)$ & $\begin{array}{l}\mathrm{t}=3.67, \mathrm{df} 61, p=0.001 \\
95 \% \mathrm{Cl} 3.8 \text { to } 13.0\end{array}$ \\
\hline $\begin{array}{l}\text { Mean (SD) Modified Survey of Activities } \\
\text { and Fear of Falling in the Elderly Scale }\end{array}$ & $28.8(8.9)$ & $20.1(4.3)$ & $\begin{array}{l}\mathrm{t}=5.24, \mathrm{df} 60.9, p<0.001 \\
95 \% \text { Cl } 5.4 \text { to } 12.3\end{array}$ \\
\hline
\end{tabular}

${ }_{\mathrm{a}}$ test for unequal variances used, as appropriate; Median in fallers = 30 and in non-fallers = 18; Mann Whitney $\mathrm{U}$ test for difference in medians $p<0.001$. BMI body mass index 
Table 3 Logistic regression analysis of the relationship between each fear of falling measure and physical activity adjusting for all other factors $(N=58)$

\begin{tabular}{|c|c|c|c|}
\hline Measure & Characteristic & Odds ratio & $95 \% \mathrm{Cl}$ \\
\hline \multirow[t]{10}{*}{ MFES } & BMl per $\mathrm{kg} / \mathrm{m}^{2}$ & 1.07 & 0.98 to 1.17 \\
\hline & \multicolumn{3}{|l|}{ Age group } \\
\hline & $<35$ years & 1 & \\
\hline & 35 to 44 years & 1.62 & 0.46 to 10.6 \\
\hline & 45 years and over & 3.45 & 0.71 to 16.7 \\
\hline & Depression & 0.93 & 0.77 to 1.14 \\
\hline & MFES score & 0.65 & 0.44 to $0.96^{*}$ \\
\hline & \multicolumn{3}{|c|}{ As above + adjusting for self-reported fall } \\
\hline & Fallen in last year & 2.79 & 0.53 to 14.7 \\
\hline & MFES Score & 0.57 & 0.36 to $0.91^{*}$ \\
\hline \multirow[t]{10}{*}{ MSAFFE } & BMl per $\mathrm{kg} / \mathrm{m}^{2}$ & 1.06 & 0.98 to 1.16 \\
\hline & \multicolumn{3}{|l|}{ Age group } \\
\hline & $<35$ years & 1 & \\
\hline & 35 to 44 years & 2.20 & 0.46 to 10.6 \\
\hline & 45 years and over & 5.06 & 1.04 to $24.5^{*}$ \\
\hline & Depression & 0.90 & 0.72 to 1.12 \\
\hline & MSAFFE score & 1.14 & 1.01 to $1.28^{*}$ \\
\hline & \multicolumn{3}{|c|}{ As above + adjusting for self-reported fall } \\
\hline & Fallen in last year & 2.53 & 0.54 to 12.0 \\
\hline & MSAFFE Score & 1.17 & 1.03 to $1.34^{*}$ \\
\hline \multirow[t]{10}{*}{ COF } & BMl per $\mathrm{kg} / \mathrm{m}^{2}$ & 1.06 & 0.98 to 1.15 \\
\hline & \multicolumn{3}{|l|}{ Age group } \\
\hline & $<35$ years & 1 & \\
\hline & 35 to 44 years & 1.69 & 0.37 to 7.8 \\
\hline & 45 years and over & 5.23 & 1.11 to $24.5^{*}$ \\
\hline & Depression & 0.96 & 0.80 to 1.16 \\
\hline & COF score & 1.08 & 0.99 to 1.18 \\
\hline & \multicolumn{3}{|c|}{ As above + adjusting for self-reported fall } \\
\hline & Fallen in last year & 1.85 & 0.43 to 8.0 \\
\hline & COF Score & 1.10 & 1.0 to 1.21 \\
\hline
\end{tabular}

BMI Body mass index, MFES Modified Falls Efficacy Scale, MSAFFE Modified Survey of Activities and Fear of Falling in the Elderly Scale, COF Consequences of Falling Scale; ${ }^{*} p<0.05$

\section{Discussion}

In this study, a high proportion of obese women under 50 years of age reported having had a fall in the previous year. Others have reported a higher probability of tripping, slipping and falls among those who are obese compared to those who are not [26-29]. Talbot et al. reported a falls rate among women aged 20 to 45 of any body mass index that is a third of that seen in our study [30]. A population study of US adults reported that among women aged 45-79 the risk of a fall in the previous 12 months was higher among those who were obese [31]. It may not be surprising then, albeit a novel finding, that, in this study, obese younger women experienced high levels of fear of falling, irrespective of the measure used. For each measure of fear of falling, mean scores were similar to those observed in studies of elderly populations and other populations with balance issues $[19,20,22,32]$. Similar to studies in the elderly, mean scores were significantly worse in obese younger women who had fallen in the last year compared to those who had not fallen [19-22].

Worse MFES and MSAFFE scores were associated with lower physical activity levels, potentially providing evidence for novel interventions to promote activity in 
this group. A recent Cochrane systematic review suggests that exercise interventions are probably effective in reducing fear of falling in community dwelling older adults [33], but there is less evidence available about the impact of psychological interventions. This was a cross-sectional study and the direction of effect is unclear. It could be that fear of falling leads to low physical activity because obese women avoid activities due to concerns about falling or it could be that low physical activity leads to more difficulties undertaking activities and, hence, concerns about falling if they undertake these activities. However, studies in the elderly have demonstrated that fear of falling precedes activity restrictions $[8,9]$. While the concerns about Damage to Identity were higher than concerns about Loss of Functional Independence, fallers were more concerned than non-fallers about Loss of Functional Independence, and it was this subscale that was associated with low activity levels. These findings suggest that there may be a benefit to focussing on falls prevention and ongoing support after falls in obese younger adults to maintain activity levels.

Given that fear of falling encapsulates a number of different concepts [7], there are a number of available scales measuring a range of constructs but all developed for older people [18]. Considerable international effort has been focussed on developing a consistent measure, the Falls Efficacy Scale International (FES-I), which has excellent validity and reliability for elderly populations [34], and is increasingly used in fear of falling research. Some may criticise our study because we did not use this measure and relied on less rigorously validated tools. In our previous study comparing 8 obese young adults with 8 non-obese young adults, a small, albeit statistically significant, higher mean score on the FES-I was observed [35]. However, we felt that the activities included in this scale might not be of sufficiently high order to discriminate between groups, or cover all the concerns, of younger obese adults [36, 37]. The preceding qualitative study confirmed this and guided the choice of measures in this study. In addition, the activity avoidance measure was chosen specifically because, in part, the study was on the potential relationship between fear of falling and physical activity. Known group differences between fallers and non-fallers provides evidence of the validity of these tools in this population, but further work is needed to determine their reliability. The study was also limited to women. In part, this was because of the small number of men who accessed weight management services at that time, but also women have been shown to have higher levels of fear of falling in the elderly and women have higher rates of falls than men [31, 38]. However, future work should also look at these issues in men who are obese.

\section{Conclusion}

Women who are obese and under 50 years of age report a high incidence of falls and fear of falling. Fear of falling appears to be associated with low levels of physical activity, although, the odds ratios were of borderline significance. This study was undertaken in a group who are already in contact with weight management services, but the findings suggest that further work is warranted to explore this important unique finding in larger, population-based cohort studies. Further elucidation will increase our understanding of the capacity of obese adults to undertake physical and incidental activities and suggest novel interventions to promote lifestyle changes and weight management or through falls prevention to reduce activity restriction. This may require the development and validation of more relevant measures for this population.

\section{Abbreviations}

BMl: Body mass index; COF: Consequences of Falling Scale; FES-I: Falls Efficacy Scale International; MFES: Modified Falls Efficacy Scale; MSAFFE: Modified Survey of Activities and Fear of Falling in the Elderly Scale: SF-IPAQ: Short Form International Physical Activity Questionnaire

\section{Acknowledgements}

We would like to acknowledge the staff and women who helped with this study.

\section{Funding}

This work was undertaken as part fulfilment of a PhD; the student bursary was funded by UCLAN. The funders had no role in the design or interpretation of this study or the study on which it is based.

\section{Availability of data and materials}

The datasets generated during the current study are not publicly available as this was not part of the informed consent process but researchers may approach the first author about reasonable requests on further analyses.

\section{Authors' contributions}

GR, PD, AM and JR were involved in the conception, design and interpretation of the study. GR designed the data collection instrument and collected the data. GR led and PD supported the statistical analysis of the data. All authors have contributed to the manuscript. All authors have read and approved the manuscript.

\section{Ethics approval and consent to participate}

Ethical approval was obtained from NRES sub-committee in North East York - Research Ethics Committee number 14/NE/0064 - and was approved by all research governance departments within NHS Trusts. Informed verbal consent was obtained and agreement implied on completion and return of the questionnaire, this was approved by the NRES ethics committee. Age was collected in five-year age groups on the advice of the NRES ethics committee to maintain patient confidentiality. Licences and permissions to use the different scales was obtained, as necessary. The qualitative study reported in the methods section of this study was approved by NRES Committee North West - Greater Manchester West 11/NW/0006 and by all research governance departments within NHS Trusts.

Consent for publication

Not applicable.

\section{Competing interests}

GR was in receipt of a PhD bursary from the University of Central Lancashire (UCLAN) and was employed by the NHS Trust where the study was based, she now works for a public obesity service in Australia. PD, JR and AM were GR's PhD supervisors. 


\section{Publisher's Note}

Springer Nature remains neutral with regard to jurisdictional claims in published maps and institutional affiliations.

\section{Author details}

${ }^{1}$ Nepean Blue Mountains Family Metabolic Health Service, Nepean Clinica School, Kingswood, New South Wales and University of Sydney, Sydney, Australia. ${ }^{2}$ Faculty of Health and Wellbeing, University of Central Lancashire, Preston, Lancashire, UK. ${ }^{3}$ Allied Health Research Unit, University of Central Lancashire, Preston, Lancashire, UK. ${ }^{4}$ Faculty of Health and Social Care, Edge Hill University, Road, Ormskirk, St Helens, Lancashire L39 4QP, UK.

Received: 27 July 2018 Accepted: 10 January 2019

Published online: 04 March 2019

\section{References}

1. Jensen MD, Ryan DH, Apovian CM, Ard JD, Comuzzie AG, et al. 2013 AHA ACC/TOS guideline for the management of overweight and obesity in adults: a report of the American College of Cardiology/American Hear Association task force on practice guidelines and the Obesity Society. Circulation. 2014;129(25 Suppl 2):S102-38.

2. Zdziarski LA, Wasser JG, Vincent HK. Chronic pain management in the obese patient: a focused review of key challenges and potential exercise solutions. J Pain Res. 2015:8:63-77.

3. Burgess $P$, Hassmenad P. Determinants of adherence to lifestyle interventions in adults with obesity; a systematic review. Clinical Obesity. 2017;7:3.

4. Hue O, Simoneau M, Marcotte J, Berrigan F, Dore J, Marceau P, et al. Body weight is a strong predictor of postural stability. Gait Posture. 2007;26(1):32-8

5. Himes CL, Reynolds SL. Effect of obesity on falls, injury, and disability. J Am Geriatr Soc. 2012;60(1):124-9.

6. Teasdale N, Simoneau M, Corbeil P, et al. Obesity alters balance and movement control. Curr Obes Rep. 2013:2:235

7. Parry S, Finch T, Dreary V. How should we manage fear of falling in older adults living in the community? BMJ. 2013;346:f2933.

8. Austin N, Devine A, Dick I, Prince R, Bruce D. Fear of falling in older women: longitudinal study of incidence, persistence and predictors. J Am Geriatr Soc. 2007;55(10):1598-603.

9. Bruce DG, Devine A, Prince RL. Recreational physical activity levels in healthy older women; the importance of fear of falling. J Am Geriatr Soc. 2002;50(1):84-9.

10. Sallinen J, Leinonen R, Hirvensaloc M, Lyyra T-M, Heikkinen E, Rantanen T. Perceived constraints on physical exercise among obese and non-obese older people. Prev Med. 2009;49(6):506-10.

11. Jackson S, Mercer C, Singer B. An exploration of factors influencing physical activity levels amongst a cohort of people living in the community after stroke in the south of England. Disabil Rehabil. 2016:1-11.

12. Collado-Mateo D, Gallego-Diaz JM, Adsur JK, Dominquez-Munoz FJ, Olivares PR, Gusi N. Fear of Falling in women with Fibromyalgia and its relation with risk of falls and balance performance. BioMed Res Int. 2015. https://doi.org/ 10.1155/2015/589014.

13. International Physical Activity Questionnaire. Guidelines for Data Processing and Analysis of the International Physical Activity Questionnaire (IPAQ): Short Form and Long Forms. November 2005. https://docs.google.com/ viewer? $\mathrm{a}=\mathrm{v} \&$ pid $=$ sites\&srcid $=$

ZGVmYXVsdGRvbWFpbnx0aGVpcGFxfGd4OjEONDgxMDk3NDU1YWRIZTM Accessed 23rd July 2018

14. Zigmond AS, Snaith RP. The hospital anxiety and depression scale. Acta Psychiatric Scandinavia. 1983;67:361-70

15. Elliott SA, Baxter KA, Davies PSW, Truby H. Accuracy of self-reported physical activity levels in obese adolescents. Journal of Nutrition and Metabolism. 2014. https://doi.org/10.1155/2014/808659.

16. Kharche JS, Ashok P, Raju RG, Balsubramanian B. Gender difference in MET score and waist to hip ratio in young adults. International Journal of Biomedical and Advanced Research. 2014:05:07.

17. Rosic G, Dey P, Richards J, Milston A. Fear of falling: the effects on activity participation in younger overweight women. Obes Facts. 2013;6(Suppl. 1): 173.

18. Jorstad EC, Hauer K, Becker C, Lamb SE. Measuring the psychological outcomes of falling: a systematic review. J Am Geriatr Soc. 2005;53:501-10.
19. Hill KD, Schwartz JA, Kalogeropoulos AJ, Gibson SJ. Fear of falling revisited. Arch Phys Med Rehab. 1996:77(10):1025-9.

20. Yardley L, Smith H. A prospective study of the relationship between feared consequences of falling and avoidance of activity in community- living older people. Gerontologist. 2002;42(1):17-23.

21. Delbaere K, Crombez G, Vanderstraeten G, Willems T, Cambier D. Fearrelated avoidance of activities, falls and physical frailty. A prospective community based cohort study. Age Ageing. 2004;33:368-73.

22. O'Halloran AM, Penard N, Galli A, Fan CW, Robertson IH, Kenny RA. Falls and falls efficacy: the role of sustained attention in older adults. BMC Geriatr. 2011;11:85.

23. Scholes S, Mindell J, Scholes S. Chapter 2: physical activity in adults. Health Survey for England 2012. Health and Social Care information Centre. p. 2013. https:/files.digital.nhs.uk/publicationimport/pub13xxx/pub13218/ hse2012-ch2-phys-act-adults.pdf. Accessed 23 July 2018

24. Peeters G, Dobson AJ, Deeg DJH, Brown WJ. A life course perspective on physical function in women. Bulletin of the World Health Organisation. 2013;91:661-70

25. Arfken CL, Lach HW, Birge SJ, Miller JP. The prevalence and correlates of fear of falling in elderly persons living in the community. Am J Public Health. 1994;84:565-70.

26. Garman CR, Franck CT, Nussbaum MA, Madigan ML. A bootstrapping method to assess the influence of age, obesity, gender and gait speed on the probability of tripping as a function of obstacle height. J Biomech. 2015; 48:1229-32

27. Fjeldstad C, Fjeldstad AS, Acree LS, Nickel KJ, Gardner AW. The influence of obesity on falls and quality of life. Dyn Med. 2008;7:4

28. Finkelstein EA, Chen H, Prabhu M, Trogdon JG, Corso PS. The relationship between obesity and injuries among U.S. adults. Am J Health Promot. 2007; 3(5):460-8.

29. Yang F, Kim J, Yang F. Effects of obesity on dynamic stability control during recovery for a treadmill-induced slip among young adults. J Biomech. 2017; 53:148-53.

30. Talbot LA, Musiol RJ, Witham EK, Metter EJ. Falls in young, middle-aged and older community dwelling adults. BMC Public Health. 2005:5:86.

31. Ylitalo KR, Karvonen-Gutierrez CA. Body mass index, falls, and injurious falls among U.S. adults: findings from the 2014 behavioral risk factor surveillance system. Prev Med. 2016;91:217-23.

32. Jonasson SB, Nilsson MH, Lexell J. Psychometrics properties of four fear of falling rating scales in people with Parkinson's disease. BMC Geriatr. 2014;14:66.

33. Kumaar A, Delbaere K, Zijlstra GAR, Carpenter H, liffe S, Masud T, et al. Exercise for reducing fear of falling in older people living in the community: Cochrane systematic review and meta-analysis. Age Ageing. 2016;45(3):345-52.

34. Yardley L, Beyer N, Hauer K, Kempen G, Piot-Ziegler C, Todd C. Development and initial validation of the falls efficacy scale-international (FES-I). Age Ageing. 2005:34:614-9.

35. Dey P, Thewlis D, McCullough K, Goodacre L, Richards, J. Quality of movement in obesity. Int J Obes 2007. 31: S211-S211.

36. Larsson UE, Mattsson E. Functional limitations linked to high body mass index, age and current pain in obese women. Int J Obes. 2001;25:893-9.

37. Larsson UE, Mattsson E. Perceived disability and observed functional limitations in obese women. Int J Obes. 2001;25:1705-12.

38. Pohl P, Ahlgren C, Nordin E, Lundquist A, Lundin-Olsson K. Gender perspectives on fear of falling using the classification of functioning as model. Disabil Rehabil. 2015:37(3):214-22.

Ready to submit your research? Choose BMC and benefit from

- fast, convenient online submission

- thorough peer review by experienced researchers in your field

- rapid publication on acceptance

- support for research data, including large and complex data types

- gold Open Access which fosters wider collaboration and increased citations

- maximum visibility for your research: over $100 \mathrm{M}$ website views per year

At BMC, research is always in progress.

Learn more biomedcentral.com/submission 